\begin{tabular}{|c|c|c|}
\hline Case Reports in & \multicolumn{2}{|c|}{ Case Rep Gastroenterol 2014;8:119-122 } \\
\hline Gastroenterology & $\begin{array}{l}\text { DOI: 10.1159/000362360 } \\
\text { Published onIIne: AprII 3, } 2014\end{array}$ & $\begin{array}{l}\text { ( ) } 2014 \text { S. Karger AG, Basel } \\
1662-0631 / 14 / 0081-0119 \$ 39.50 / 0 \\
\text { www.karger.com/crg }\end{array}$ \\
\hline & \multicolumn{2}{|c|}{$\begin{array}{l}\text { This is an Open Access article licensed under the terms of the Creative Common } \\
\text { Attribution-NonCommercial } 3.0 \text { Unported license (CC BY-NC) (www.karger.com/OA } \\
\text { license), applicable to the online version of the article only. Distribution permitted for non } \\
\text { commercial purposes only. }\end{array}$} \\
\hline
\end{tabular}

\title{
Cholecystocutaneous Fistula after Percutaneous Gallbladder Drainage
}

\author{
Stahs Pripotnev ${ }^{a} \quad$ Andrew Petrakos ${ }^{b, c}$ \\ ${ }^{a}$ Schulich School of Medicine and Dentistry, The University of Western Ontario, and \\ ${ }^{b}$ Department of Surgery, Schulich School of Medicine and Dentistry, The University of \\ Western Ontario, London, Ont.; ${ }^{C}$ Department of Surgery, Windsor Regional Hospital - \\ Metropolitan Campus, Windsor, Ont., Canada
}

\section{Key Words}

Cholecystitis · Cholecystocutaneous fistula · Laparoscopic cholecystectomy · Percutaneous drainage $\cdot$ Gallstones

\begin{abstract}
Cases of cholecystocutaneous fistulas are now a rare occurrence as a result of rapid diagnosis and treatment. We present a case of cholecystocutaneous fistula developing after the removal of a percutaneous drain for the treatment of acute cholecystitis. Re-occurring infection and presence of gallstones led to fistulization of the gallbladder fundus and the development of a tract along the path created by the drain. The patient presented with re-occurring right upper quadrant abdominal pain, purulent discharge from the fistulous opening and expulsion of multiple gallstones. She underwent laparoscopic cholecystectomy and fistula excision.

(c) 2014 S. Karger AG, Basel
\end{abstract}

\section{Introduction}

Cholecystocutaneous fistulas are a rare complication of cholecystitis. Their occurrence was first described in 1670 by Thilesus. However, at that time fistulas were a common complication of chronic and untreated cholecystitis [1]. According to a 2005 study, 226 cases have been reported in total, with fewer than 25 in the last 50 years [2]. The reduced incidence in current times can be attributed to more rapid diagnosis and treatment with antibiotics or surgery. Although occurring in acalculous cholecystitis and carcinoma of the gallbladder, fistulas are still most commonly associated with gallstones [3, 4]. Obstruction of the cystic duct leads to an increase in gallbladder pressure and reduced perfusion with necrosis, which consequently causes gallbladder perforation. The contents of the gallbladder 
Pripotnev and Petrakos: Cholecystocutaneous Fistula after Percutaneous Gallbladder Drainage

may then empty into the peritoneal cavity and an abscess may form or a fistula may develop through adherence to the duodenum, colon or abdominal wall, often via the fundus of the gallbladder [4]. The right upper quadrant is the most common location for the exit tract of the fistula, but locations such as the gluteal region, umbilicus and right groin have also been documented [2]. Cholecystocutaneous fistulas are most often seen in elderly women over the age of 60 , likely due to coexistent disease and non-specific symptoms interfering with diagnosis [5]. Cases have been reported in patients aged as young as 24 years [4].

\section{Case Report}

A white 85-year-old female with hypertension and a previous history of breast biopsy underwent endoscopic retrograde cholangiopancreatography with sphincterotomy after initially presenting on May 3, 2011 with common duct stones. The patient was initially seen in the emergency department complaining of a 3-day history of sharp intermittent epigastric and right upper quadrant pain radiating to the central back. She reported occasional nausea and vomiting but no food association. She denied acholic stools but admitted to dark urine. On physical examination she was afebrile with stable vital signs. Mild scleral icterus was noted, but there were no signs of jaundice or lymphadenopathy. Her abdomen was soft, nondistended and mildly tender to palpation with a positive Murphy's sign. Routine blood work demonstrated an elevated white blood cell count of 16.1, no abnormalities on SMA7, elevated lipase $>3,000$, and elevated liver function testing including an alkaline phosphatase of 215, a bilirubin of 41, an AST of 100, a GGT of 305 and an ALT of 194. Abdominal ultrasound and computed tomography revealed cholelithiasis with mild edema of the gallbladder wall. Clinical evidence of mild jaundice accompanied by blood work abnormalities and positive radiological signs led to the diagnosis of acute calculous cholecystitis, common bile duct stones up to $7 \mathrm{~mm}$ in size and biliary gallstone pancreatitis. She was treated conservatively with intravenous antibiotics and underwent endoscopic retrograde cholangiopancreatography with sphincterotomy for removal of several stones of various sizes. Percutaneous cholecystostomy was then carried out for drainage of the gallbladder after development and medical control of atrial fibrillation. She was discharged home on May 16 after 13 days in hospital. She was to be followed by surgery for elective laparoscopic cholecystectomy.

On June 1, 2011 she was re-admitted to the hospital with a left lower lobe pulmonary embolism. She was treated with intravenous heparin and subsequently with Coumadin. On June 27, 2011 the percutaneous drain was removed at her request.

In early August 2011, she re-developed right upper quadrant discomfort; furthermore, she noted some purulent drainage from the percutaneous drain site and extrusion of approximately 30 gallstones. She had several follow-up ultrasounds which identified a fistulous tract measuring $0.78 \mathrm{~cm}$ in diameter communicating with the external opening in the right upper quadrant (fig. 1). An irregular hypoechoic area just inside the subcutaneous tissue measuring $4.1 \times 2.7 \mathrm{~cm}$ was presumed to represent a contracted gallbladder. Common duct diameter was measured at $0.48 \mathrm{~cm}$. Plain films of the area showed no abnormalities. Plans were made for laparoscopic cholecystectomy and management of her cholecystocutaneous fistula on February 22, 2012, once she finished her Coumadin regiment.

In the morning of the operation, on February 22, 2012, the patient's INR was still elevated at 1.8 and the surgery was re-scheduled for a month later. On April 18, 2012 the patient underwent laparoscopic cholecystectomy and fistula division (fig. 2). Three additional gallstones were found in the gallbladder at the time of the operation. The surgery proceeded 
Pripotnev and Petrakos: Cholecystocutaneous Fistula after Percutaneous Gallbladder Drainage

successfully with no complications. The patient made an uneventful recovery and was discharged home 1 day later.

\section{Discussion}

We present the case of an 85-year-old white female who was diagnosed with a cholecystocutaneous fistula that developed as a complication following removal of a percutaneous drain that was used to treat her acute cholecystitis. Re-occurrence of her cholecystitis after drain removal and the presence of gallstones promoted the production of a fistula along the pre-existing tract of the drain. Her concurrent treatment with anticoagulants for a pulmonary embolism delayed the definitive management of her cholecystitis and fistula. Fortunately, the patient remained in reasonably good health throughout the waiting period from time of fistula diagnosis to surgery.

Cholecystectomy is the definitive treatment for this condition. More conservative approaches such as percutaneous cholecystotomy have been used in high-risk patients, leading to spontaneous closure of the fistula [6]. However, in this case the fistula developed through the old drain tract, so surgical intervention was employed. As with uncomplicated cholecystitis, laparoscopic techniques are favorable compared to open surgery and thus a laparoscopic cholecystectomy was undertaken in this case. The gallstones removed during cholecystectomy were of orange-brown color consistent with cholesterol stones. Histopathology showed chronic cholecystitis with no signs of dysplasia or malignancy.

Although fistula formation is now a rare complication of cholecystitis, it remains a possibility and should be considered in the differential diagnosis of any fistulous tract in the right abdominal wall. We have demonstrated that previous percutaneous drainage of an acute gallbladder infection can promote the formation of such a fistula if the infection is not properly dealt with or re-occurs. Physicians should be prepared to recognize this complication in patients after drain removal and prior to definitive surgery.

\section{References}

1 Horhammer CI: Über estraperitoneale Perforatio der Gallenblase. Munch Med Wochenschr 1916;10: 1451-1452.

-2 Yüceyar S, Ertürk S, Karabiçak I, Onur E, Aydoğan F: Spontaneous cholecystocutaneous fistula presenting with an abscess containing multiple gallstones: a case report. Mt Sinai J Med 2005;72:402-404.

-3 Birch BR, Cox SJ: Spontaneous biliary fistula uncomplicated by gallstones. Postgrad Med J 1991;67:391-392.

4 Vasanth A, Siddiqui A, O’Donnell K: Spontaneous cholecystocutaneous fistula. South Med J 2004;97:183185.

5 Lyon C, Clarke DC: Diagnosis of acute abdominal pain in older patients. Am Fam Physician 2006;74:15371544.

6 Davies MG, Tadros E, Gaine S, McEntee GP, Gorey TF, Hennessy TP: Combined internal and external biliary fistulae treated by percutaneous cholecystlithotomy. Br J Surg 1989;76:1258. 
Pripotnev and Petrakos: Cholecystocutaneous Fistula after Percutaneous Gallbladder Drainage

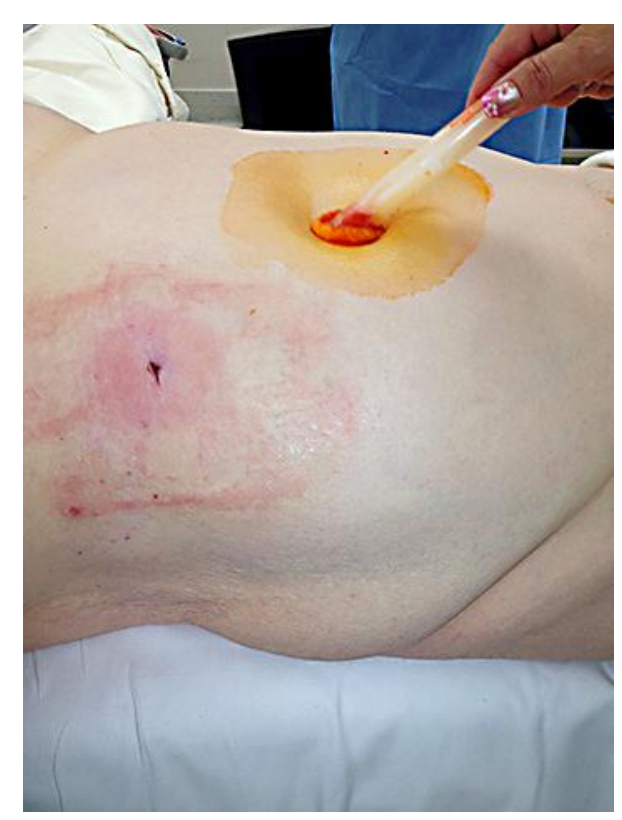

Fig. 1. Location of the pre-operative right upper quadrant fistula exit communicating from the patient's gallbladder.

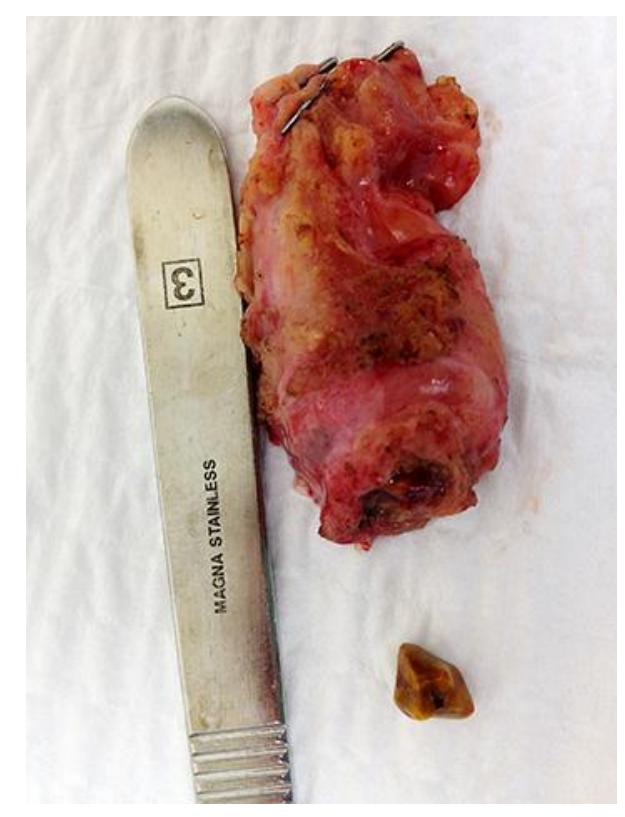

Fig. 2. The excised gallbladder with fistula division at the fundus. Gallstone and scalpel handle are shown for reference. 